\title{
Use of Endotracheal Sodium Bicarbonate for Pulmonary Clearance in Pediatric Patients
}

\author{
Kimberly McMahon ${ }^{1}$, Katlyn Burr ${ }^{1}$, Kelly Massa ${ }^{1}$, Peter Anley ${ }^{1}$, Carl Gerdine ${ }^{1}$, John \\ Giamalis $^{1}$, and Meg Frizzola ${ }^{1}$ \\ ${ }^{1}$ Alfred I DuPont Hospital for Children
}

May 19, 2020

\begin{abstract}
Background: Few guidelines exist to guide pulmonary clearance therapies for children receiving invasive mechanical ventilation. In our institution, we have used sodium bicarbonate solution instilled via tracheal tube to assist with secretion clearance and improve atelectasis. Despite reports of its use, there is very little literature to characterize sodium bicarbonate via tracheal tube in clinical practice. Methods: We performed an IRB-approved, retrospective chart review in a single center of all patients who received sodium bicarbonate via tracheal tube over a 5-year period. We collected data on how sodium bicarbonate was used and analyzed for any reported improvement in respiratory status after its use. Results: Fifteen patients were reviewed. Most received $2.4 \%$ sodium bicarbonate via tracheal tube for an average of three doses of an average of $3.1 \mathrm{~mL}$ instilled. Most patients had documented improvement in chest radiograph appearance, and several were able to be significantly weaned from mechanical ventilator settings immediately following use of sodium bicarbonate. Most had thinner, smaller, and clearer secretions following use of sodium bicarbonate. There were no adverse events related to use of sodium bicarbonate. Conclusions: Sodium bicarbonate given via tracheal tube was safe in our group of patients. There was improvement in chest radiograph appearance, secretion tenacity, and ventilatory needs in most of our patients. This was a small, retrospective study of pediatric patients with very complex medical conditions, and most were also receiving other forms of pulmonary clearance concomitant with sodium bicarbonate. Further study is warranted in the form of prospective, randomized, blinded trials.
\end{abstract}

\section{Hosted file}

Burr bicarb MS.doc available at https://authorea.com/users/324136/articles/452428-use-ofendotracheal-sodium-bicarbonate-for-pulmonary-clearance-in-pediatric-patients

\section{Hosted file}

Table 1 Burr.docx available at https://authorea.com/users/324136/articles/452428-use-ofendotracheal-sodium-bicarbonate-for-pulmonary-clearance-in-pediatric-patients

\section{Hosted file}

Table 2 Burr.docx available at https://authorea.com/users/324136/articles/452428-use-ofendotracheal-sodium-bicarbonate-for-pulmonary-clearance-in-pediatric-patients

\section{Hosted file}

Table 3 Burr.docx available at https://authorea.com/users/324136/articles/452428-use-ofendotracheal-sodium-bicarbonate-for-pulmonary-clearance-in-pediatric-patients

\section{Hosted file}


Table 4 Burr.docx available at https://authorea.com/users/324136/articles/452428-use-ofendotracheal-sodium-bicarbonate-for-pulmonary-clearance-in-pediatric-patients

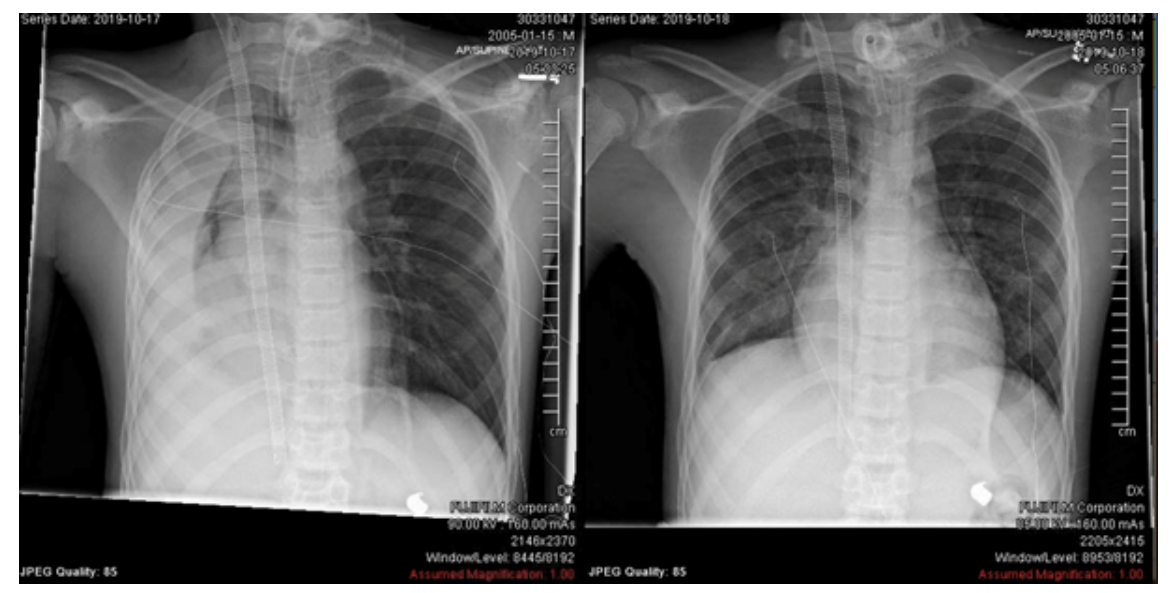

